\title{
EPIGENETIC REGULATION OF ADIPOCYTES PHENOTYPE: IMPLICATION FOR PERIVASCULAR ADIPOSE TISSUE CONTRIBUTION TO CARDIOMETABOLIC DISEASES
}

\section{Karl Blirando \\ Weatherall Institute of Molecular Medicine, Nuffield Department of Clinical Medicine, University of Oxford, Oxford, UK}

\begin{abstract}
Perivascular adipose tissue (PVAT) has emerged in the past decades as an integral part of the vasculature (tunica adiposa), contributing by the release of adipokines, to important physiological process such as vascular tone regulation. The metabolic syndrome is associated with an increase deposition of PVAT and the development of atherosclerosis. Whereas healthy PVAT protect the vasculature from inflammation, lipid accumulation and hypothermia, the dysfunctional PVAT observed in the metabolic syndrome favour many features of atherosclerosis such as endothelial dysfunction, vascular smooth muscle proliferation and inflammation. The down- and up-regulation of adiponectin, leptin and nerve growth factor, respectively in the dysfunctional PVAT perfectly illustrates this change. Phenotypically, healthy PVAT resembles the thermogenic brown and beige adipocytes, however, recent data suggest a loss of PVAT thermogenic phenotype during the metabolic syndrome in a process called "PVAT whitening". This review will provide a current perspective on the factors susceptible to influence PVAT epigenetics and the consequences of PVAT dysfunction on cardiometabolic diseases.
\end{abstract}

Adipobiology 2016, 8: 19-34

Key words: tunica adiposa, WAT, BAT, cardiometabolic diseases, fetal programming, leptin, adiponectin, nerve growth factor, AMP-activated kinase 


\section{Abbreviations used}

ADCF: Adipose derived constricting factor; ADRF: Adipose derived relaxing factor; AMPK-5': Adenosine monophosphateactivated protein kinase; BAT: Brown adipose tissue; CMD: Cardiometabolic diseases; CpG: 5'-C-phosphate-G-3'; DNA: Deoxyribonucleic acid; DNMT: DNA methyltransferase; EHMT1: Euchromatic histone lysine n-methyltransferase 1; FNDC5: Fibronectin type III domain-containing protein 5; H2S: Hydrogen sulphide; HDAC: Histones deacetylase; HFD: High fat diet; IL-6: Interleukin-6; iNOS: inducible nitric oxide synthase; JAK: Janus kinase; KDM1: Lysine (K)-specific demethylase 1; KMT1: Lysine (K)-specific methyltransferases 1; LIF: Leukaemia Inhibitory factor; LSD1: Lysine-specific histone demethylase 1; MCP-1: Monocyte chemoattractant protein-1; Myf5: Myogenic factor 5; Myh11: Myosin heavy chain 11; NGF: Nerve growth factor ;NO: Nitric oxide; p75 ${ }^{\mathrm{NTR}}$ : p75 (pan) neurotrophin receptor; Pax7: Paired box homeotic gene 7; PDGFRa: Platelet derived growth factor receptor alpha; PGC$1 \alpha$ : Peroxisome proliferator-activated receptor $\gamma$ coactivator- $1 \alpha$; PPAR $\gamma$ : Peroxysome proliferator activated receptor gamma; PRDM16: PR domain containing 16; PVAT: Perivascular adipose tissue; SAT: Subcutaneous adipose tissue; SM22a: Smooth muscle protein 22-alpha; STAT3: Signal transducer and activator of transcription 3; TDG: Thymine DNA glycosylase; TET: Ten-eleven translocation; TNFa: Tumour necrosis factor alpha; TrkA: Tropomyosin-related kinase receptor A; UCP-1: Uncoupling protein-1; VAT: Visceral adipose tissue; WAT: White adipose tissue; WHO: World Health Organization

\section{Prologue}

In our post-industrial society, the combination of the abundance of processed food, sedentary life style, stress, and exposure to endocrine disruptor favours the explosion of obesity. According to the World Health Organization (WHO) obesity has doubled since 1980, and by 2030 some studies suggest that almost half (42\%) of adult in the United States could be affected (Finkelstein et al. 2012). During the same period the burden of cardiometabolic diseases (CMD) has also grown making them for the first time in human history the leading cause of premature mortality ahead of infectious diseases (WHO report 2008). About 260 years ago the Italian physician Morgagni described the association between hyperuricemia, visceral obesity, hypertension, obstructive sleep apnoea and atherosclerosis (Crepaldi et al. 2006). It was not before 1998 that the term metabolic syndrome was defined by the WHO as a syndrome comprising type 2 diabetes or impaired glucose tolerance associated with at least two out of the four other factors, namely high blood pressure, high blood fat, obesity and microalbuminuria (Grundy et al. 2004, Crepaldi et al. 2006). Since then the scientific community has deployed constant effort to understand the interconnections between the different components of the metabolic syndrome leading to atherosclerosis development.

\section{Introduction}

Adipose tissue is widely distributed throughout the human body and can be subdivided according to its anatomical location. Subcutaneous adipose tissue (SAT) and visceral adipose tissue (VAT) are the main pools of adipose tissue and account for 82 97\% and $10-15 \%$ of total body fat respectively (Gastaldelli et al. 2010, Lee et al. 2013). However, small adipose tissue depots are also found in the bone marrow, skeletal muscles and mammary glands (Rosen et al. 2014). In the past decades perivascular adipose tissue (PVAT) has emerged as an integral part (tunica adiposa) of human arteries (Chaldakov et al. 2009, 2012, 2014; AyalaLopez and Watts 2016) and veins of large, medium and small sizes with the notable exception of cerebral vessels (Houben et al. 2012, Szasz et al. 2013, Brown et al. 2014), and represent an average of 3\% of total fat in human (Gastaldelli et al. 2010; Lee et al. 2013). In the small vessels of some organs, however, PVAT may be constituted by the adipose depots embedding this organ as it is the case for the pericoronary/epicardial PVAT (Britton et al. 2011). It is now accepted that PVAT is not only a connective tissue, providing the vessel with mechanical protection, but also a regulator of vascular functions through the secretion of many adipokines with vasoactive, pro- and anti-inflammatory, and neuro-metabotrophic properties (Chaldakov et al. 2014; Kostopoulos et al. 2014; Iacobellis 2016). Although adipocytes are the main component of PVAT it also consists of nerves and resident immune cells (e.g. macrophages, mast cells) whose interactions ensure vascular homeostasis (Chaldakov et al. 2014, Ayala-Lopez and Watts 2016). Whereas SAT and VAT are the main contributors to the systemic adipokines level, the proximity of PVAT with the vasa vasorum may allow PVAT-derived adipokines to reach the inner vascular cells (i.e. vascular smooth muscle and endothelial cells) at high concentration and thereby strongly impact vascular function. Thus, it has been shown that PVAT exert anticontractile functions through the release of adipose derived relaxing factors (ADRF) such as adiponectin, hydrogen sulphide $\left(\mathrm{H}_{2} \mathrm{~S}\right), \mathrm{NO}$ and prostacyclin (Wojcicka et al. 2011, Nava et al. 2016). On the other hand, PVAT can mediate nerve dependant vasoconstriction by releasing adipose derived constricting factors (ADCF) such as superoxide anion, angiotensin II and endothelin-1 (Gao et al. 2007).

Obesity is associated with an increase in PVAT deposition, which is strongly related to atherosclerotic plaque development (Mahabadi et al. 2010, Maurovich-Horvat et al. 2011). Moreover, 
in a swine model of obesity the increases in PVAT deposition negatively correlate with coronary vasodilatation (Owen et al. 2013). Accumulating data suggest also a phenotypic switch of PVAT during metabolic syndrome development which can be summarized under the term "PVAT dysfunction". The dysfunctional PVAT is characterized by a loss of its anticontractile property, and an increase in the release of proinflammatory and proangiogenic adipokines (Chang et al. 2013; Kostopoulos et al. 2014). These adipokines, by promoting endothelial dysfunction, macrophage chemotaxis, together with the proliferation of vascular SMC and fibroblasts, contribute to the vascular remodelling and the progression of atherosclerotic plaque. On the other hand, when compared to other fat depots such as SAT and VAT, mouse PVAT was found to be resistant to a high fat diet (HFD) induced inflammation (Fitzgibbons et al. 2011). The protective role of PVAT could be linked to its thermogenic potential that regulates intravascular temperature, increases plasma triglyceride clearance and confer resistance to inflammation. Therefore, it is important to identify the molecular (i.e. Mediators, signalling pathway, epigenetic factor) determinants of PVAT phenotype in health and disease. Several studies suggest that in utero and long term exposure to the metabolic syndrome could lead to a loss of PVAT thermogenic ability by modifying its epigenetic memory. In the past decades epigenetics has emerged as a new level of gene regulation involving modification of DNA accessibility by post-translational modification of histones (e.g. phosphorylation, acetylation, and methylation) and DNA methylation. Recent studies in humans (Mamun et al. 2009, Oken 2009, Fraser et al. 2010) and rodents (Samuelsson et al. 2008, Shankar et al. 2008) models have shown the links between maternal obesity or weight gain during pregnancy and metabolic disorders such as obesity, glucose intolerance and CMD in offspring. In this review, we are presenting the recent evidences of epigenetic regulation of adipocytes phenotype relevant to PVAT biology in health and disease.

\section{PVAT phenotype in the spectrum of adipocytes phenotype}

In addition to differences in location, there are also substantial functional differences between adipose tissue depots. Two main types of adipocytes are distinguished in human and mouse. Most adipocytes of SAT and VAT constitute the white adipose tissue (WAT). The white adipocytes constituting WAT are characterized by a unilocular large lipid droplets, small peripheral nucleus, few mitochondria's and are mainly responsible for energy storage in the form of lipids (Rosen et al. 2014). On the other hand thermogenic or brown adipose tissue (BAT) in humans is found in cervical, supraclavicular, paravertebral, mediastinal, and peri-renal regions (Sacks et al. 2013). The brown adipocytes constituting BAT are smaller, present multilocular lipid droplets, centralized nucleus, and higher numbers of mitochondria. The main physiological function of brown adipocyte is to maintain body temperature and avoid hypothermia. The thermogenic capacity of brown adipocytes relies on the expression of the uncoupling protein-1 (UCP-1) within the mitochondria (Rosen et al. 2014). This protein by catalysing a proton leak across the inner mitochondrial membrane disconnect fatty acid oxidation from ATP production, thus producing heat (Rosen et al. 2014). Recently a third category of adipocyte called beige or brite (for brown in white adipocytes) has been characterized (Chechi et al. 2013). These cells are mainly induced in SAT by stimuli such as cold exposure and $\beta$-adrenergic stimulation. Similar to brown adipocytes, beige adipocytes express high levels of UCP-1 whose expression is required for their thermogenic function (Lee et al. 2013). In human most studies on PVAT has been made on the pericoronary/epicardial and periaortic adipose tissue and conclude that human PVAT phenotype resembles beige/brown adipocytes and is characterized by a small size, multilocular lipid droplets, abundant mitochondria, as well as high expression of UCP-1 (Sacks et al. 2013, Brown et al. 2014). In agreement with the findings in human, studies in mice showed that aortic PVAT present a large similarity to BAT and is also resistant to diet-induced inflammation (Fitzgibbons et al. 2011). Brown adipocytes in rodents has been shown to improve several characteristics of the metabolic syndrome, such as hyperglycaemia, insulin resistance and the excess of free fatty acid characterizing dyslipidaemia (Bartelt et al. 2011, Shimizu et al. 2015, Villarroya 2016). In accordance with a similar protective effect of PVAT, Chang et al showed that PVAT free mice had impaired ability to regulate triglyceride levels and intravascular temperature (Chang et al. 2012). In conclusion the thermogenic potential of most PVAT depots (with the exception of mesenteric PVAT) is associated with vasculoprotective functions. Therefore, it is crucial to understand the mechanisms regulating PVAT thermogenic phenotype, and PVAT dysfunction in order to prevent, and manage the vascular diseases associated with the metabolic syndrome.

\section{Role of epigenetics in adipocytes differentiation and PVAT phenotypic diversity}

From a developmental perspective, brown and white adipocytes arise from two different precursors (Fig. 1A). Whereas brown adipocytes derived from a $\mathrm{Pax}^{+} / \mathrm{Myf5}^{+}$stem cells involved in skeletal muscle development, white and beige adipocytes are derived from a common PAX7//Myf5/PDGFR- $\alpha^{+}$precursor (Brown et al. 2014). In a very interesting article Chang et al demonstrated that specific deletion of PPAR $\gamma$ in SM22a ex- 
A

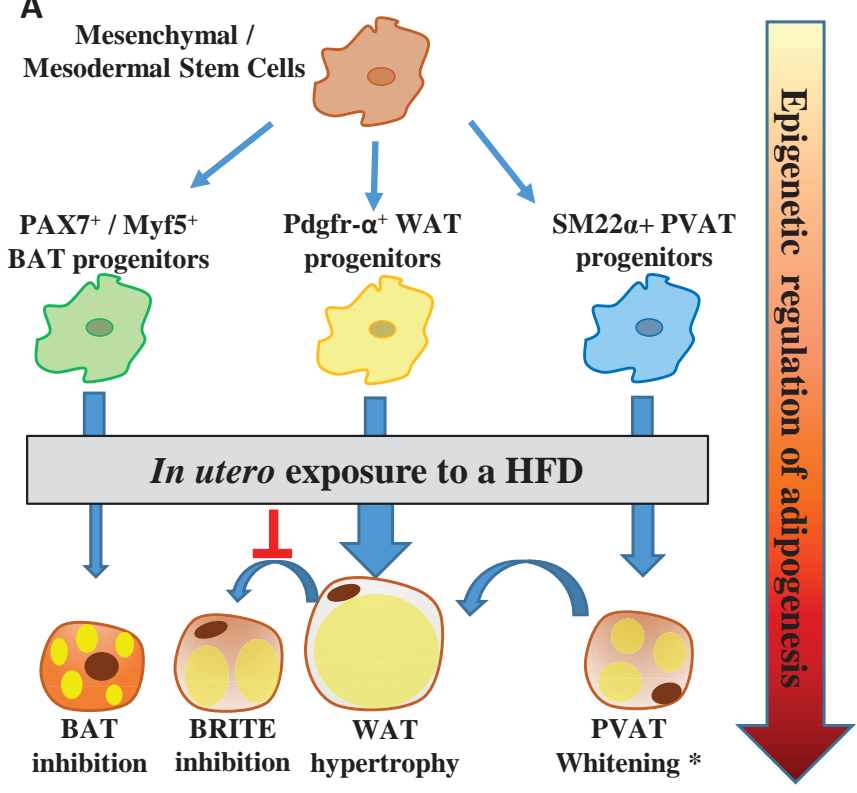

B

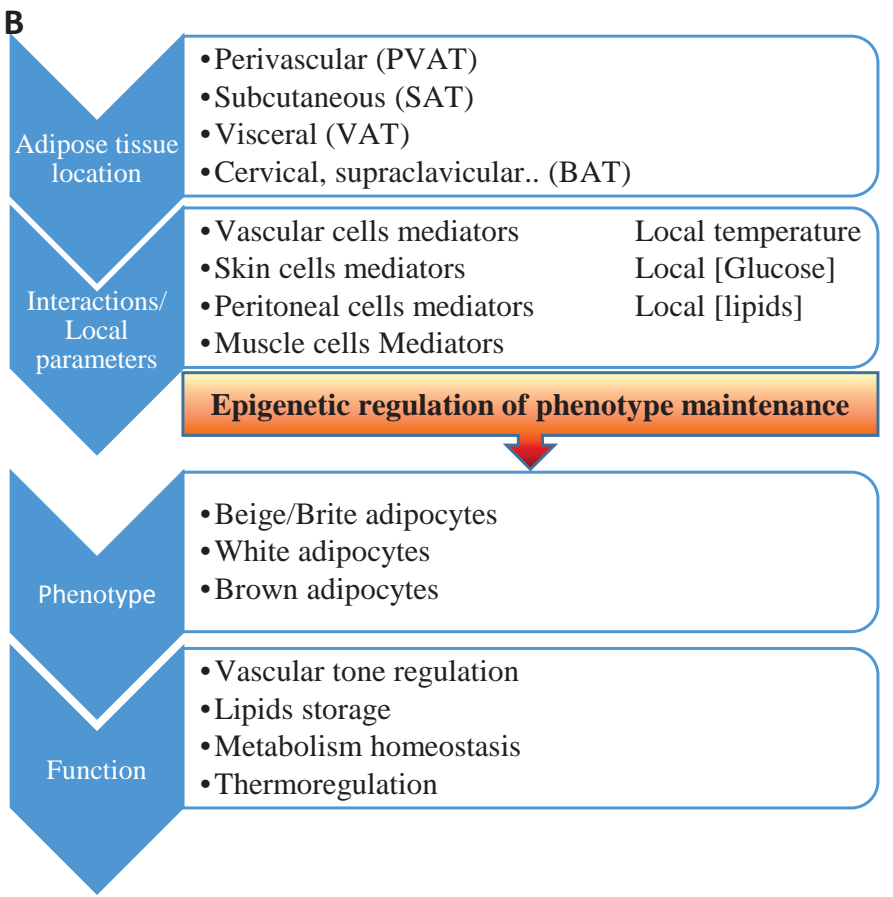

Figure 1. A. Representation of adipocytes foetal programming induced by in utero exposure to a high fat diet (HFD). Epigenetics plays an important role in the development of most tissues including adipose tissue and allow the generation of brown (BAT), brown in white (BRITE), white (WAT) and perivascular (PVAT) adipose tissue depots from mesenchymal/mesodermal stem cells (Siersbaek et al. 2012). In utero exposure to a HFD, by generating inflammation and the loss of metabolic homeostasis induces a reduction of thermogenic adipocytes while inducing WAT hypertrophy and PVAT "whitening". Whether this alteration also affects the generation of the intermediate progenitors remains unknown. Adapted from (Brown et al. 2014). B. Hypothetical model of adipose tissue phenotype diversity based on location. According to the results of Satoor et al. (2011) adipose tissues location define their exposure to local parameters such as glucose concentration ([glucose]), leading to epigenetic regulation of their phenotype. Beyond [glucose] other mediators derived from nearby resident cells, such as, cytokines, growth factors may also regulate adipocytes phenotype through epigenetic regulation resulting in specific phenotypes and functions. ${ }^{*}$ Not applicable to mesenteric PVAT.

pressing cells (i.e. Vascular smooth muscle cells) impairs aortic and mesenteric PVAT development without any effect on BAT and WAT development (Chang et al. 2012). This strongly suggests that mouse PVAT derived from a precursor of the vascular smooth muscle cell lineage. Consequently, compared to others fat depots such as SAT, PVAT present a reduced adipogenic potential and a heightened pro-inflammatory phenotype (Chatterjee et al. 2009, Gil-Ortega et al. 2015). Despite these differences in origin, both brown and beige adipocytes express the transcription factor PRDM16 which play a critical role in the thermogenic differentiation of adipocytes. Interestingly, it has been shown that PRDM16 promotes the thermogenic differentiation of adipocytes through its association with the euchromatic histone-lysine N-methyltransferase 1 (EHMT1). Through this interaction PRDM16 repress the genetic program leading to skeletal muscle differentiation (Ohno et al. 2013). Similar to PVAT development, it has been shown recently that a subset of beige adipocytes induced by cold, is derived from a vascular smooth muscle cell (SMC) precursor expressing myosin heavy chain 11 (Myh11 ${ }^{+}$) (Long et al. 2014, Berry et al. 2016). Interestingly the expression of PRDM16 in vascular smooth muscle cells is able to turn them into beige adipocytes (Long et al. 2014). This suggests that PRDM16 through interactions with EHMT1 or another epigenetic regulator could repress vascular smooth muscle cell differentiation in the SM22 $\alpha^{+}$precursor and promote PVAT differentiation. This hypothesis is also supported by the fact that human epicardial adipose tissue (peri-coronary adipose tissue) display great similarities with beige adipocytes 
(Sacks et al. 2013). Despite a common developmental path PVAT phenotype varies according to location in human and mouse. Thus, in mice the phenotype of PVAT in the thoracic aorta resembles BAT, whereas mesenteric PVAT resembles WAT. Finally, aortic and renal adipocytes resembles beige adipocytes (Brown et al. 2014). These observations support a high plasticity of PVAT adipocytes and the critical role of environmental and cellular interactions in adipocytes phenotype. In a remarkable work, Satoor et al showed that transfer of VAT in the subcutaneous space was able to modify the phenotype of the engrafted VAT by modifying its epigenetic memory (Satoor et al. 2011). Indeed, they showed that the high glucose concentration in the mesenteric circulation was able to epigenetically repress VAT expression of adipokines (i.e. adiponectin, leptin, resistin and visfatin) by recruiting the histone demethylase LSD1 and KMT1 (Satoor et al. 2011). This could explain the fact that mesenteric PVAT unlike others present a phenotype of white adipocytes. Interestingly, diabetes, which is characterized by hyperglycaemia is associated with PVAT inflammation that may result from a "PVAT whitening" (Lastra et al. 2015). Beyond glucose concentration other physiological parameters varying with location, such as temperature, exposure to myokines, inflammatory and neuromediators have been shown to influence the terminal differentiation of adipocytes (Wang et al. 2016). This suggests that the phenotype of each fat depot results from the sensing and integration of many environmental factors and that, epigenetics may be a critical mechanism controlling adipose tissue diversity and adaptation (Fig. 1B). By screening a collection of epigenetic compounds recently identified the histone demethylase LSD1/KDM1 as a key regulator of brown adipogenesis (Chen et al. 2016). Using RNA interference and knock-out mice, they further demonstrated that LSD1/KDM1 promotes brown adipogenesis through Wnt pathway inhibition and stimulation of UCP-1 expression (Chen et al. 2016). In another study KDM1A has been shown to promote adipogenic differentiation and repress the expression of inflammatory mediators (i.e. IL-6) in the 3T3-L1 pre-adipocyte cell line (Hanzu et al. 2013). Although the role of LSD1/KDM1 in PVAT has not been studied yet it is interesting to notice that LSD1/KDM1 deficient mice (i.e. LSD1/ $\mathrm{KDM} 1+/-$ ) are more sensitive then there WT counterpart to salt induced hypertension due to alterations in NO-cGMP induced vascular relaxation (Pojoga et al. 2011). Whether this phenotype is due to a "PVAT whitening" remain to be demonstrated. This illustrates the potential role of epigenetic factors controlling the thermogenic adipocyte program in vascular biology. In a recent article Inagaki et al provided a complete review of the transcriptional and epigenetic regulators controlling brown and beige adipocytes differentiation that could be used to further inves- tigate the path of PVAT development and function (Inagaki et al. 2016).

In an effort to uncover the mechanisms behind adipocytes phenotypic diversity Gehrke et al (2003) studied the DNA methylation profile of different fat depots (i.e. abdominal and gluteal) in humans. They showed that DNA methylation profile of genes involved in fatty acid and triglyceride metabolism correlates with their levels of expression in these depots resulting in differential fatty acid and triglycerides saturation. These results clearly demonstrate that epigenetic regulation is an important aspect of adipocytes functional diversity. But recent data's also suggest a role for epigenetic regulation in dysfunctional adipocytes. Indeed, increases in the DNA methylation profile of genes relevant to adiposity in SAT of humans correlate with body mass index (BMI), android adipose mass, android:gynoid adipose ratio and trunk:limb adipose ratio (Agha et al. 2015). Moreover, differential methylation of genes related to obesity has also been reported in the SAT of obese woman (Arner et al. 2015) and post-obese woman whose obesity is characterized by adipocytes hyperplasia (Dahlman et al. 2015). Thereby, epigenetic modifications such as histones and DNA methylation are not only involved in adipocytes differentiation, but also in the maintenance of depots specific phenotype and the acquisition of a pathologic phenotype in patients with obesity.

\section{PVAT dysfunction caused by fetal programming}

Further evidences of the epigenetic regulation of PVAT phenotype in health and disease has been brought by experimental models of foetal programming (Fig. 1A). In these models the foetus undergoing epigenetic regulation of its fat development is exposed to a pathologic maternal milieu induced by HFD (Laker 2013). The interference of this pathological maternal milieu (i.e. hyperglycaemia, dyslipidaemia and inflammation) with the ongoing epigenetic regulation of adipogenesis results in obesity, glucose intolerance and CMD in the offspring that are transmitted to the next generations (Laker 2013). Thus, Zaborska et al (2016) recently showed that the offspring of obese rats fed an HFD during pregnancy and lactation lost the anticontractile function of their PVAT despite being fed a normal diet for 12 or 24 weeks after weaning. Furthermore this loss of anticontractile function resulted in hypertension at 24 weeks old of age. From a mechanistic perspective, the study showed that the loss of anticontractile effect of PVAT was due to the release of ADCF and a decrease in nitric oxide (NO) bioavailability (Zaborska et al. 2016). This study suggests that in utero exposure to metabolic and adipokines imbalance, could imprint a pathological memory in adipocytes predisposing the offspring to hypertension. Beyond the loss of anti-contractile properties, in utero exposure 
to a HFD has also been shown to favour atherosclerosis development and a pro-inflammatory phenotype of PVAT especially by increasing the expression of the chemokines MCP-1 (Wakana et al. 2015). The contribution of PVAT dysfunction to atherosclerosis development has been further demonstrated by transplantation experiments. Indeed transplantation of PVAT from 8 weeks old mice exposed in utero to a HFD was associated with a twofold increased in atherosclerotic plaque development in the nearby artery when compared to transplantation of PVAT from mice exposed in utero to a normal diet (Wakana et al. 2015). A recent report also showed that coronary atherosclerosis induced by a HFD is accompanied by a transition of the epicardial fat phenotype from brown to white (Wang et al. 2015). This transition was characterized by a decrease in the number of mitochondria as well as in the expression of UCP-1 and PPAR $\gamma$ (Wang et al. 2015). Consistently it has been shown that the offspring of mice fed a HFD during lactation present a reduction in BAT depots and a reduced thermogenic capacity of their adipocytes (Liang et al. 2016). One of the major regulator of PPAR $\gamma$ function and UCP-1 expression during the development of thermogenic adipocytes is the peroxisome proliferator-activated receptor $\gamma$ coactivator-1a (Pgc-1 $\alpha)$. Interestingly a HFD has been shown to repress PGC-1 1 expression in skeletal muscle through methylation of its promoter (Laker et al. 2014). Thus the epigenetic repression of PGC-1 $1 \alpha$ in PVAT could explain the impaired UCP-1 and PPAR $\gamma$ expression observed in epicardial fat of rats exposed to a HFD. UCP-1 expression in adipocytes has been shown to be regulated through both DNA methylation and histones modification in response to cold exposure (Shore et al. 2010). The detrimental effect of a possible "PVAT whitening" on atherosclerosis development is provided by transplant experiments showing that VAT transplant is more proatherogenic than SAT which include numbers of thermogenic (i.e. beige adipocytes) adipocytes (Ohman et al. 2011). It is therefore important to find new targets allowing the maintenance of PVAT thermogenic phenotype and the prevention of its "whitening".

\section{Effect of exercise training on PVAT function and adipocytes thermogenic program}

Whereas in utero exposure to a HFD is associated with PVAT "whitening" in offspring, studies on the effect of exercise training suggest a possible "re-browning" of PVAT. Indeed, in a rat model of metabolic syndrome (i.e. obese Zucker rats) associated with PVAT dysfunction (i.e. loss of anti-contractile function, decreased UCP-1 expression, increased inflammatory mediator expression) exercise training have been shown to improve UCP-1 expression and to inhibit the release of IL- 6 and TNFa by PVAT (DeVallance et al. 2016). Recent reports showed that exercise training was able to improve the dysfunction of adipocytes induced by a HFD in rats through induction of beige adipocytes in their WAT. The authors observed an exercise dependant increase in fibronectin type III domain-containing protein 5 (FNDC5) the precursor of the myokine irisin (Rocha-Rodrigues et al. 2016, Rocha-Rodrigues et al. 2016; for exercise-adiponectin link see Öztürk et al in this volume of Adipobiology). Previously irisin has been reported to induce white fat browning through stimulation of UCP-1 expression (Bostrom et al. 2012). Interestingly a recent article showed that irisin restores the anticontractile function of mouse PVAT in a model of obesity induced by a HFD by increasing its expression of heme oxygenase and adiponectin while reducing that of superoxide and TNFa (Hou et al. 2016). However, human data's failed to show a substantial impact of training exercise on circulating irisin and SAT browning (Norheim et al. 2014). Although the authors did not investigate the contribution of epigenetics to the "re-browning" of PVAT in their models, studies in humans showed that a 6 months exercise training was able to change the DNA methylation profile of 7663 genes in adipocytes (Ronn et al. 2013). Interestingly, one of the genes found to be hyper methylated and therefore inhibited in adipocytes after the 6 months exercise training was the histone deacetylase 4 (HDAC4). Further investigations using the pre-adipocyte cell line 3T3-L1 showed that HDAC4 silencing was associated with increase basal and insulin-induced lipogenesis (Ronn et al. 2013). Moreover the exercise training has been shown to prevent epigenetic repression of PGC-1alpha in the skeletal muscle of mice exposed in utero to a HFD (Laker et al. 2014). Such an effect in PVAT could explain the beneficial effect of exercise training on mouse PVAT dysfunction induced by foetal programming. Further experiments are needed to determine whether the improvement in PVAT function associated with exercise training could be due a myokines dependant "rebrowning" induced through epigenetic regulation.

\section{Epigenetic regulation of adiponectin expression and effect on cardiometaboilic diseases}

Adiponectin is the main adipokine secreted by adipose tissue and represent in an average $0.01 \%$ of plasma protein. Adiponectin play important metabolic functions by promoting fatty acid oxidation, glucose uptake and preventing glucose induced ROS synthesis (Shimomura et al. 2006; Van de Voorde et al. 2013). Animal studies in models of CMD showed that adiponectin has cardioprotecive, anti-inflammatory, -oxidant, -atherogenic, and -apoptotic properties (Chow et al. 2007, Goncalves et al. 2015). Moreover down regulation of its receptor in obese patients is related to insulin resistance and the intramuscular deposition of lipids (Yamauchi et al. 2001). The protective role of adiponectin 
in CMD is further supported by the inverse correlation existing between its plasma concentration, BMI and the risk of hypertension (Cnop et al. 2003). Consistently, adiponectin has been shown to contribute to mouse PVAT anticontractile function (Lynch et al. 2013). Therefore the downregulation of adiponectin is a hallmark of adipose tissue dysfunction associated with the metabolic syndrome and thereby has been studied intensively. A recent study of adiponectin gene methylation statue in adipose tissue of obese patients showed a positive correlation with BMI suggesting that the downregulation of adiponectin expression associated with adipose tissue dysfunction is due to epigenetic repression (Houde et al. 2015). In a model of in utero exposure to a HFD researchers confirmed the role of adiponectin promoter methylation as the probable cause of decrease circulating adiponectin associated with the metabolic syndrome. In another research article using the same model, it has been shown that epigenetic regulation of adiponectin also involves histone modifications. In this study adiponectin promoter repression in WAT was associated to a decreased acetylation and an increase methylation of histone $\mathrm{H} 3$ at lysine 9 (Masuyama et al. 2012). The decrease in histone $\mathrm{H} 3$ acetylation could be due to the action of the Histone Deacetylase 9 (HDAC9), since its inhibition in a model of chronic consumption of a HFD in mice was associated with an increase adiponectin expression and enhanced energy expenditure by promoting Beige adipogenesis (Chatterjee et al. 2014). Further studies showed that the epigenetic changes induced by in utero exposure to a HFD in the adiponectin promoter are transmitted up to 3 generations (Masuyama et al. 2015). Although such epigenetic modifications in adiponectin gene has not been directly studied in PVAT several studies have shown decreases in adiponectin expression at the mRNA and protein level in the PVAT of human diseased vessels (Ozen et al. 2015). Moreover the detrimental effect of adiponectin repression in PVAT on atherosclerosis development has recently been shown. Indeed engraftment of PVAT from adiponectin deficient mice in a model of collar induced carotid atherosclerosis resulted in the accelerated atherosclerotic plaque formation (Li et al. 2015). The protective effect of adiponectin in this model was due to its ability to promote macrophages autophagy (Li et al. 2015). Antonopoulos et al also recently highlighted the role of PVAT derived adiponectin as an important anti-oxidant mediator in the internal mammary artery of patients suffering with type II diabetes (Antonopoulos et al. 2015). However a recent analysis of adiponectin expression in the PVAT of patients undergoing carotid endarterectomy showed a 2 fold increase of its expression in symptomatic plaques, suggesting a detrimental role of adiponectin in the stability of atherosclerotic plaques (Sharma et al. 2015). In conclusion adiponectin expression in PVAT strong- ly influence vascular biology and is regulated in adipocytes partly through epigenetic mechanisms. Further experiments are required to fully understand the mechanisms involved in PVAT adiponectin repression.

\section{Epigenetic regulation of leptin expression and effects on cardiometabolic diseases}

Unlike adiponectin, the plasma concentration of leptin, another important adipokine mainly secreted by adipocytes, is positively correlated to obesity $(31.3 \pm 24.1 \mathrm{ng} / \mathrm{ml}$ vs $7.5 \pm 9.3 \mathrm{ng} / \mathrm{ml}$ in nonobese subjects) (Considine et al. 1996). However, these patients also present leptin resistance due to decreased expression of the leptin receptor. Leptin at first has been involved in energy metabolism and appetite regulation and was perceived has a protective adipokine with anti-obesogenic and anti-diabetic properties (Oral et al. 2002). However, from a cardiovascular perspective, leptin has been shown to promote several processes involved in CMD such as platelet aggregation, oxidative stress, vascular smooth muscle cell proliferation, and inflammation (Beltowski 2006). The role of epigenetics and particularly DNA methylation in leptin expression associated with obesity has recently been studied in SAT, VAT and blood cells of severely obese patients. The data showed an inverse correlation between leptin promoter methylation in blood cells and BMI, suggesting a role for leptin promoter demethylation in the hyperleptinemia associated with obesity (Houde et al. 2015). The contribution of epigenetics to the dysfunctional leptin system associated with the metabolic syndrome has also been studied using offspring of mice fed with a HFD during pregnancy. In addition, to increase in body mass, dyslipidaemia and glucose intolerance the offspring also present hyperleptinemia (Khalyfa et al. 2013). The authors showed that the hyperleptinemia induced by a HFD was due to the hypomethylation of CpG sites in leptin promoter. Conversely the expression of the leptin receptor in visceral fat was downregulated due to hypermethylation of its promoter (Khalyfa et al. 2013). In another study using the same model it has been shown that a HFD increases leptin expression in adipocytes through hypermethylation of the lysine 20 of histone $\mathrm{H} 4$ at its promoter (Masuyama et al. 2012). Similar to the modifications in adiponectin promoter the complete loss of the epigenetic marks induced by in utero exposure to a HFD in leptin promoter occurs after 3 generations of return to a normal diet (Masuyama et al. 2015). The increases expression of leptin in PVAT of patients with CMD has been observed at the mRNA and protein level (Ozen et al. 2015), however the role of epigenetics in this increase remains to be established. Further studies on the epigenetic regulation of leptin and adiponectin expression in PVAT could lead in the future to the identification of targets, allowing 
the improvement of PVAT function in individuals affected by the metabolic syndrome.

\section{Nerve growth factor a potential marker of adipose tissue inflammation in cardiometaboilic diseases}

Nerve growth factor (NGF) is a prototype member of the protein family of neurotrophins (that induce the survival and development of neurons) discovered by Rita Levi-Montalcini in the early 1950's. Since then NGF has been involved in a wide range of human diseases, including, neurodegenerative and psychiatric disorders and CMD (Aloe et al. 2013; Yanev et al. 2013). Nerve growth factor exerts its biological effects on cells by binding to a high affinity receptor called tropomyosin-related kinase receptor A (TrkA) and a low affinity receptor named p75 (pan) neurotrophin receptor ( $\left.\mathrm{p} 75^{\mathrm{NTR}}\right)$. Whereas TrkA activation mediates protective functions, especially in neurodegenerative disorders, $\mathrm{p} 75^{\mathrm{NTR}}$ on the other hand, has been shown to mediate proNGF-induced apoptosis (Aloe et al. 2013). Therefore the relative expression of both receptors deeply influences NGF pathophysiology.

From a physiological perspective NGF expression in PVAT and other adipose depots may be related to the recruitment and maintenance of innervation as recently demonstrated for the perivascular innervation of mouse neovessels (Goda et al. 2016). In a recent review Ayala-Lopez and Watt (2016) highlighted the potential role of the sympathetic innervation and the adrenergic system of PVAT in obesity-associated hypertension. In addition to hypertension, altered interactions between nerves and adipocytes in PVAT may contribute to atherosclerosis development. Indeed, advanced coronary atherosclerosis in human is associated with a reduced amount of NGF and an increase in mast cells and vasa vasorum number and $\mathrm{p} 75^{\mathrm{NTR}} \mathrm{ex}-$ pression in the subepicardial adipose tissue (Chaldakov et al. 2004). Both WAT and BAT has been shown to express NGF and brain-derived neurotrophic factor (BDNF) in mouse (Sornelli et al. 2009) and in human (Nisoli et al. 1996, Peeraully et al. 2004). And obesity was associated with an increase of NGF circulating level in women (Bullo et al. 2007) and its expression in SAT (Atanassova et al. 2014). Moreover, in a model of type 1 diabetes induced by streptozotocin injection in rat, NGF expression has been shown to increase in both WAT and BAT (Sornelli et al. 2009). Nevertheless, several studies showed that NGF expression in fat depots of obese patients was primarily due to nonadipocyte cells, including stromal vascular cells (Fain 2010). In fact, analysis of NGF expression during human adipogenesis in vitro revealed a downregulation in differentiated adipocytes (Wang et al. 2005). Consistent with this result treatment of adipocytes with the PPAR $\gamma$ agonists, rosiglitazone (Ryan et al.
2008) and 15-deoxy- $\Delta 12,14$-PGJ2 (Bullo et al. 2005) results in reduced NGF secretion. On the other hand, NGF expression in vitro is consistently increase in adipocytes by several atherosclerosis related mediators such as TNFa (Peeraully et al. 2004, Ryan et al. 2008), LPS (Ryan et al. 2008) and prostaglandins (Bullo et al. 2005). This suggests that the increase expression of NGF in PVAT could be due to the recruitment of NGF expressing immune cells and a "PVAT whitening" induced by inflammatory mediators. This hypothesis is supported by results showing that stimuli promoting brown adipogenesis such as cold and norepinephrine were able to decrease the NGF expression in BAT (Nisoli et al. 1996). In contrast with these results other has shown increased expression of NGF in BAT of rats and hamsters exposed to cold (Nechad et al. 1994).

Whereas the role of epigenetics in NGF expression by adipocytes has not been studied yet, results obtained in other cell types support this possibility. Thus, in a model of chronic neuropathic pain induced by chronic constriction injury of the rat sciatic nerve, Tao et al showed that infusion of the brainstem nucleus raphe magnus with an HDAC inhibitor was associated with an increase in histone $\mathrm{H} 4$ acetylation at the NGF promoter resulting in increased NGF expression (Tao et al. 2016). Such an association between histone $\mathrm{H} 4$ acetylation and NGF expression has also been observed in the central amygdala in a model of addiction induced by morphine stimulation in rat (Bie et al. 2012). In addition to histones acetylation, epigenetic regulation of NGF also involves methylation of its promoter. Indeed, during alcohol withdrawal in human the decrease in circulating NGF correlates with the increased methylation of CpG islands in the NGF promoter of blood cells (Heberlein et al. 2013). Finally, it has been shown in human colorectal cancer cells that the expression of the NGF receptor $\mathrm{p} 75^{\mathrm{NTR}}$ was also frequently repressed by methylation of its promoter (Yang et al. 2015).

In conclusion NGF is consistently induced in adipocytes in vitro by inflammatory mediators and in vivo by CMD with an important inflammatory component. Further studies are required to define the sources, modalities of regulation and the outcomes of NGF increases in healthy and dysfunctional PVAT associated with CMD with particular emphasize on inflammation and epigenetics.

\section{Role of inflammation in the epigenetic regulation of PVAT dysfunction}

Inflammation is an important player of the metabolic syndrome linking obesity to insulin resistance and has been involved in the initiation as well as the rupture of atherosclerotic plaques (Bentzon et al. 2014). Therefore PVAT in patients affected by the metabolic syndrome is exposed to the influence of systemic 
and local inflammatory mediators secreted respectively by dysfunctional SAT/VAT and damaged vascular cells and inflammatory cells (e.g. Macrophages) (Verhagen et al. 2011, FernandezAlfonso et al. 2013, Castellon et al. 2016). In a recent article Kim Ay et al (2015) investigated the regulation of adiponectin expression in adipose tissue of obese patients and identified the DNA methyl transferase 1 (DNMT1) as the responsible for the epigenetic silencing of adiponectin in these cells. Whereas adiponectin repression, has been reported in response to endoplasmic reticulum stress, mitochondrial dysfunction, hypoxia or inflammation, they found that only proinflammatory cytokines such as IL-1 $\beta$ and TNF $\alpha$ was able to induce DNMT1 expression in adipocytes (Kim et al. 2015). Interestingly, in a mouse model of PVAT inflammation induced by endovascular injury the associated inhibition of adiponectin expression in PVAT was absent in TNFa deficient mice and rescued by adjunction of TNFa to the perivascular area of the vessel (Takaoka et al. 2010). Moreover, in a mouse model of type 1 diabetes associated with repression of adiponectin expression in PVAT, Infliximab (TNFa blocking antibody) therapy restored adiponectin expression in mouse PVAT and improves endothelial nitric oxide-mediated vasodilation (Nacci et al. 2016). Both results strongly support a role for TNFa/DNMT1 in the epigenetic repression of adiponectin observed in dysfunctional PVAT. Since IL- $1 \beta$ is also an inducer of DNMT1 it could be involved in the repression of adiponectin expression and PVAT thermogenic program. Indeed IL-1 $\beta$ stimulation has been shown to inhibit the expression of UCP-1 induced by cold in vivo and $\beta$-adrenergic stimulation of adipocytes in vitro (Goto et al. 2016).

The role of inflammation in the demethylation of the leptin gene promoter on the other hand has not been reported yet. Active demethylation can be achieved by the action of the teneleven translocation (TET) and the thymine DNA Glycosylase (TDG) family enzymes (Kohli et al. 2013). To date, no report showed a positive regulation of these enzymes by inflammatory mediators in adipocytes. However a recent work aimed at investigating the role of epicardial fat in a rabbit model of coronary atherosclerosis showed that IL-6 stimulation of peri-coronary fat was able to increase leptin expression through activation of the JAK-STAT3 pathway (Wang et al. 2015). Interestingly, LIF, a cytokine belonging to the IL- 6 family of cytokine, has been shown to maintain embryonic stem cell pluripotency through the regulation of several DNA demethylases (e.g. DNMT1, 3a/b and 3I) and histones deacetylases (HDACs) in a JAK-STAT3 pathway dependant fashion (Tang et al. 2013). These results suggest that Il-6 could upregulate leptin expression in PVAT by decreasing the methylation of its promoter and thereby aggravate atherosclerosis development. The promotion of PVAT dysfunction is not restricted to IL-6 and TNFa, since in a model of inflammation induced by a HFD it has been shown that Oncostatin $M$ expression was increased and responsible for the reduced BAT development and SAT browning observed in this model (Sanchez-Infantes et al. 2016). Further studies are required to better understand the contribution of epigenetics to the PVAT dysfunction induced by inflammatory mediators.

\section{Role of the AMP-activated protein kinase in the epigenetic regulation of PVAT phenotype}

AMP-activated protein kinase (AMPK) is a serine/threonine protein kinase playing a central role in intracellular energy sensing and whole body metabolism (Almabrouk et al. 2014). Therefore AMPK has been shown to play important role in the regulation of adipocytes metabolism as well as in endothelial and vascular smooth muscle cell function (Almabrouk et al. 2014).

Inhibition of AMPK in response to a HFD has been reported in many rat tissues as an early event preceding hyperglycaemia or systemic inflammation (Lindholm et al. 2013). Similar to what observed in the offspring of mice fed a HFD, AMPK-1 deficient mice also present a loss of the anti-contractile potential of their PVAT (Almabrouk et al. 2016). The authors further showed that this loss of anti-contractile function was due to impaired adiponectin secretion (Almabrouk et al. 2016). Knowing the role of epigenetics in PVAT adiponectin repression induced by a HFD, one may think that AMPK-1 could be involved in the epigenetic regulation of BAT and PVAT. Indeed, it has been shown that an AMPK-1 deficiency in mouse is associated with impaired BAT development due to an epigenetic repression of PRDM16 expression (Yang et al. 2016). In fact the authors showed that AMPK-1 regulates the isocitrate dehydrogenase 2, an enzyme involved in the production of $\alpha$-ketoglutarate a metabolite require for TET mediated DNA demethylation. Thereby in AMPK-1 deficient mice the lack of a-ketoglutarate prevent PRDM16 promoter demethylation and mRNA expression leading to the inhibition of the development of their thermogenic fat (Yang et al. 2016).

The involvement of AMPK in epigenetic regulation of thermogenic adipogenesis may also explain the resistance of PVAT and BAT to the inflammation induced by a HFD. Indeed a recent report showed that the protective cardiovascular effects, of a plant derived steroid sapogenin named diogenin was mediated through AMPK activation (Chen et al. 2016). In a rat model of PVAT inflammation and endothelial dysfunction induced by a HFD the authors showed that diogenin treatment increases the basal AMPK expression and prevent the decrease induced by a HFD. The increase AMPK activity, then inhibits the PVAT expression of TNFa, IL-6, MCP-1 and iNOS induced by a HFD 
while promoting adiponectin, PPAR $\gamma$ and arginase- 1 expression (Chen et al. 2016). Moreover, using an in vitro model of PVAT/ endothelium interaction induced by exposure of PVAT to fatty acids (i.e. palmitic acid) it has been shown that, activation of AMPK in PVAT was able to prevent its release of inflammatory mediators and thereby its inhibition of the endothelial dependant vasodilatation (Sun et al. 2014). These latter authors found that the beneficial effects of AMPK activation was lost in the presence of nicotinamide, an inhibitor of the deacetylase and the key epigenetic regulator sirtuin 1 (SIRT1). However the exact interaction linking AMPK and SIRT1 in PVAT resistance to a HFD remains to be fully elucidated. In addition to its potential epigenetic regulation of inflammatory genes SIRT1 could also improve PVAT function by inducing mitochondrial biogenesis. Indeed Mice overexpressing SIRT1 under the control of its own promoter, has been shown to be resistant to the metabolic damages (i.e. adipose mass gain, glucose intolerance, hepatic steatosis, inflammation) induced by a HFD in particular by activating the PGC-1 $\alpha$ leading to increased mitochondrial biogenesis and higher energy expenditure (Pfluger et al. 2008). AMPK has been involved in endothelial, vascular smooth muscle cells and adipose tissue dysfunction associated with the metabolic syndrome (Almabrouk et al. 2014). A better understanding of its beneficial effect on PVAT function through epigenetic regulation of key adipokines such as leptin and adiponectin could help find new targets for managing cardiovascular diseases.

\section{Coda}

There is growing evidence that PVAT dysfunction is a key aspect in the pathogenesis of CMD induced by the metabolic syndrome. However PVAT research still represents a small percentage of research effort in adipobiology. Although PVAT resembles brown/ beige adipocytes, it arises from a distinct vascular smooth muscle progenitor (a cell lineage yet to be confirmed independently by other investigators) showing its singularity among adipocytes and its definitive belonging to the vascular structure. Therefore, it is difficult to determine to what extent findings in brown and beige adipocytes can be applied to PVAT. The data presented in this review suggest that epigenetics may play a central role in adipogenesis, the maintenance of adipocytes phenotype in adulthood (Fig. 1) and their dysfunction during metabolic syndrome (Fig. 2). The improvements in PVAT dysfunction induced by exercise training potentially through epigenetic regulation support the promises of targeting PVAT epigenetic program in preventing and managing CMD associated with the metabolic syndrome.

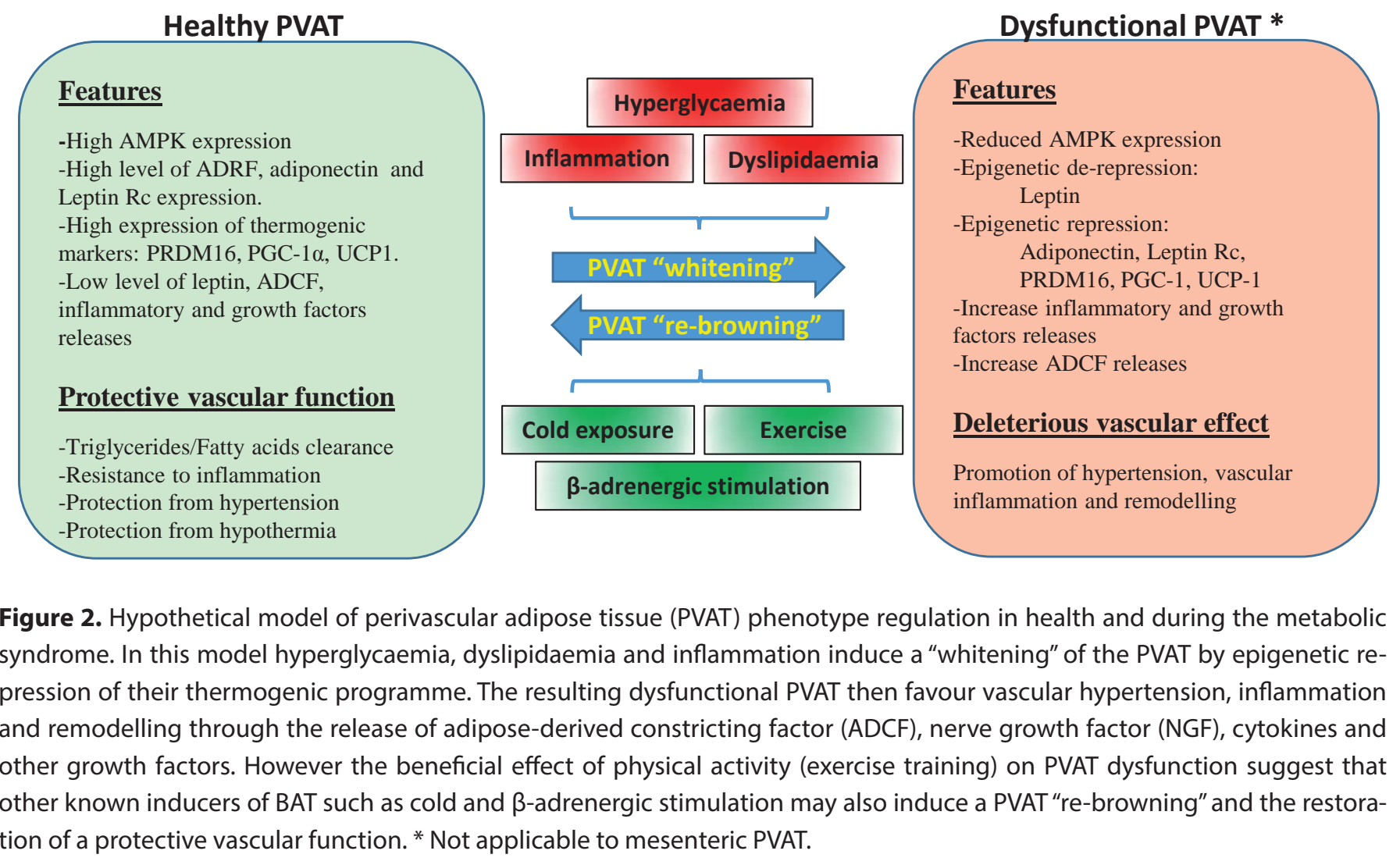


Conflicts of interest statement: The authors declare that the research was conducted in the absence of any commercial or financial relationships that could be construed as a potential conflict of interest.

\section{References}

1. Agha G, Houseman EA, Kelsey KT, Eaton CB, Buka SL, Loucks EB. Adiposity is associated with DNA methylation profile in adipose tissue. Int J Epidemiol 2015; 44: 1277 1287. DOI: 10.1093/ije/dyu236.

2. Almabrouk TA, Ewart MA, Salt IP, Kennedy S. Perivascular fat, AMP-activated protein kinase and vascular diseases. $\mathrm{Br}$ J Pharmacol 2014; 171: 595-617. DOI: 10.1111/bph.12479.

3. Almabrouk TA, Ugusman AB, Katwan OJ, Salt IP, Kennedy S. Deletion of AMPKalpha1 attenuates the anticontractile effect of perivascular adipose tissue (PVAT) and reduces adiponectin release. Br J Pharmacol 2016. DOI: 10.1111/ bph.13633.

4. Aloe L, Chaldakov GN. The multiple life of nerve growth factor: Tribute to Rita levi-Montalcini (1909-2012). Balkan Med J 2013; 30: 4-7. DOI: 10.5152/balkanmedj.2013.003.

5. Antonopoulos AS, Margaritis M, Coutinho P, Shirodaria C, Psarros C, Herdman L, et al. Adiponectin as a link between type 2 diabetes and vascular NADPH oxidase activity in the human arterial wall: the regulatory role of perivascular adipose tissue. Diabetes 2015; 64: 2207-2219. DOI: 10.2337/ db14-1011.

6. Arner P, Sinha I, Thorell A, Ryden M, Dahlman-Wright K, Dahlman I. The epigenetic signature of subcutaneous fat cells is linked to altered expression of genes implicated in lipid metabolism in obese women. Clin Epigenetics 2015; 7: 93. DOI: 10.1186/s13148-015-0126-9.

7. Atanassova P, Hrischev P, Orbetzova M, Nikolov P, Nikolova J, Georgieva E. Expression of leptin, NGF and adiponectin in metabolic syndrome. Folia Biol (Krakow) 2014; 62: 301-306

8. Ayala-Lopez N, Watts SW. New actions of an old friend: perivascular adipose tissue's adrenergic mechanisms. $\mathrm{Br} \mathrm{J}$ Pharmacol 2016. DOI: 10.1111/bph.13663.

9. Bartelt A, Bruns OT, Reimer R, Hohenberg H, Ittrich H, Peldschus $\mathrm{K}$, et al. Brown adipose tissue activity controls triglyceride clearance. Nat Med 2011; 17: 200-205. DOI: 10.1038/nm.2297.

10. Beltowski J. Leptin and atherosclerosis. Atherosclerosis 2006; 189: 47-60. DOI: 10.1016/j.atherosclerosis.2006.03.003.

11. Bentzon JF, Otsuka F, Virmani R, Falk E. Mechanisms of plaque formation and rupture. Circ Res 2014; 114: 18521866. DOI: 10.1161/CIRCRESAHA.114.302721.
12. Berry DC, Jiang Y, Graff JM. Mouse strains to study coldinducible beige progenitors and beige adipocyte formation and function. Nat Commun 2016; 7: 10184. DOI: 10.1038/ ncomms10184.

13. Bie B, Wang Y, Cai YQ, Zhang Z, Hou YY, Pan ZZ. Upregulation of nerve growth factor in central amygdala increases sensitivity to opioid reward. Neuropsychopharmacology 2012; 37: 2780-2788. DOI: 10.1038/npp.2012.144.

14. Bostrom P, Wu J, Jedrychowski MP, Korde A, Ye L, Lo JC, et al. A PGC1-alpha-dependent myokine that drives brownfat-like development of white fat and thermogenesis. $\mathrm{Na}$ ture 2012; 481: 463-468. DOI: 10.1038/nature10777.

15. Britton KA, Fox CS. Perivascular adipose tissue and vascular disease. Clin Lipidol 2011; 6: 79-91. DOI: 10.2217/ clp.10.89.

16. Brown NK, Zhou Z, Zhang J, Zeng R, Wu J, Eitzman DT, et al. Perivascular adipose tissue in vascular function and disease: a review of current research and animal models. Arterioscler Thromb Vasc Biol 2014; 34: 1621-1630. DOI: 10.1161/ATVBAHA.114.303029.

17. Bullo M, Peeraully MR, Trayhurn P. Stimulation of NGF expression and secretion in 3T3-L1 adipocytes by prostaglandins PGD2, PGJ2, and Delta12-PGJ2. Am J Physiol Endocrinol Metab 2005; 289: E62-67. DOI: 10.1152/ajpendo.00008.2005.

18. Bullo M, Peeraully MR, Trayhurn P, Folch J, Salas-Salvado J. Circulating nerve growth factor levels in relation to obesity and the metabolic syndrome in women. Eur J Endocrinol 2007; 157: 303-310. DOI: 10.1530/EJE-06-0716.

19. Castellon X, Bogdanova V. Chronic inflammatory diseases and endothelial dysfunction. Aging Dis 2016; 7: 81-89. DOI: 10.14336/AD.2015.0803.

20. Chaldakov GN, Fiore M, Stankulov IS, Manni L, Hristova MG, Antonelli A, et al. Neurotrophin presence in human coronary atherosclerosis and metabolic syndrome: a role for NGF and BDNF in cardiovascular disease? Prog Brain Res 2004; 146: 279-289. DOI: 10.1016/S0079-6123(03)46018-4

21. Chaldakov GN, Fiore M, Ghenev P, Tuncel N, Rancic G, Atanassova P, et al. State-of-the-artery: Periadventitial adipose tissue (tunica adiposa). Biomed Rev 2009; 20: 41-44.

22. Chaldakov GN, Beltowsky J, Ghenev PI, Fiore M, Panayotov P, Rancic G, et al. Adipoparacrinology - vascular periadventitial adipose tissue (tunica adiposa) as an example. Cell Biol Int 2012; 36: 327-330. DOI: 10.1042/CBI20110422

23. Chaldakov GN, Fiore M, Ghenev PI, Beltowski J, Rancic G, Tuncel N, et al. Triactome: neuro-immune-adipose interactions. Implication in vascular biology. Front Immunol 2014; 5: Article 130. DOI: 10.3389/fimmu.2014.00130 
24. Chang L, Milton H, Eitzman DT, Chen YE. Paradoxical roles of perivascular adipose tissue in atherosclerosis and hypertension. Circ J 2013; 77: 11-18. DOI: 10.1253/circj. CJ-12-1393

25. Chang L, Villacorta L, Li R, Hamblin M, Xu W, Dou C, et al. Loss of perivascular adipose tissue on peroxisome proliferator-activated receptor-gamma deletion in smooth muscle cells impairs intravascular thermoregulation and enhances atherosclerosis. Circulation 2012; 126: 1067-1078. DOI: 10.1161/CIRCULATIONAHA.112.104489

26. Chatterjee TK, Basford JE, Yiew KH, Stepp DW, Hui DY, Weintraub NL. Role of histone deacetylase 9 in regulating adipogenic differentiation and high fat diet-induced metabolic disease. Adipocyte 2014; 3: 333-338. DOI: 10.4161/ adip. 28814

27. Chatterjee TK, Stoll LL, Denning GM, Harrelson A, Blomkalns AL, Idelman G, et al. Proinflammatory phenotype of perivascular adipocytes: influence of high-fat feeding. Circ Res 2009; 104: 541-549. DOI: 10.1161/CIRCRESAHA.108.182998

28. Chechi K, Carpentier AC, Richard D. Understanding the brown adipocyte as a contributor to energy homeostasis. Trends Endocrinol Metab 2013; vol. 24. DOI: .10.1016/j. tem.2013.04.002

29. Chen Y, Kim J, Zhang R, Yang X, Zhang Y, Fang J, et al. Histone Demethylase LSD1 Promotes Adipocyte Differentiation through Repressing Wnt Signaling. Cell Chem Biol 2016; 23: 1228-1240. DOI: 10.1016/j.chembiol.2016.08.010.

30. Chen Y, Xu X, Zhang Y, Liu K, Huang F, Liu B, et al. Diosgenin regulates adipokine expression in perivascular adipose tissue and ameliorates endothelial dysfunction via regulation of AMPK. J Steroid Biochem Mol Biol 2016; 155: 155-165. DOI: 10.1016/j.jsbmb.2015.07.005.

31. Chow WS, Cheung BM, Tso AW, Xu A, Wat NM, Fong CH, et al. Hypoadiponectinemia as a predictor for the development of hypertension: a 5-year prospective study. Hypertension 2007; 49: 1455-1461. DOI: 10.1161/HYPERTENSIONAHA.107.086835.

32. Cnop M, Havel PJ, Utzschneider KM, Carr DB, Sinha MK, Boyko EJ, et al. Relationship of adiponectin to body fat distribution, insulin sensitivity and plasma lipoproteins: evidence for independent roles of age and sex. Diabetologia 2003; 46: 459-469. DOI: 10.1007/s00125-003-1074-z.

33. Considine RV, Sinha MK, Heiman ML, Kriauciunas A, Stephens TW, Nyce MR, et al. Serum immunoreactiveleptin concentrations in normal-weight and obese humans. $N$ Engl J Med 1996; 334: 292-295. DOI: 10.1056/ NEJM199602013340503.
34. Crepaldi G, Maggi S. The metabolic syndrome: a historical context. Diabetes Voice 2006; 51: 8-10.

35. Dahlman I, Sinha I, Gao H, Brodin D, Thorell A, Ryden M, et al. The fat cell epigenetic signature in post-obese women is characterized by global hypomethylation and differential DNA methylation of adipogenesis genes. Int J Obes (Lond) 2015; 39: 910-919. DOI: 10.1038/ijo.2015.31.

36. DeVallance E, Fournier S, Lemaster K, Moore C, Asano S, Bonner $\mathrm{D}$, et al. The effects of resistance exercise training on arterial stiffness in metabolic syndrome. Eur J Appl Physiol 2016; 116: 899-910. DOI: 10.1007/s00421-016-3348-4.

37. Fain JN. Release of inflammatory mediators by human adipose tissue is enhanced in obesity and primarily by the nonfat cells: a review. Mediators Inflamm 2010; 2010: 513948. DOI: 10.1155/2010/513948.

38. Fernandez-Alfonso MS, Gil-Ortega M, Garcia-Prieto CF, Aranguez I, Ruiz-Gayo M, Somoza B. Mechanisms of perivascular adipose tissue dysfunction in obesity. Int J Endocrinol 2013; 2013: 402053. DOI: 10.1155/2013/402053.

39. Finkelstein EA, Khavjou OA, Thompson H, Trogdon JG, Pan L, Sherry B, et al. Obesity and severe obesity forecasts through 2030. Am J Prev Med 2012; 42: 563-570. DOI: 10.1016/j.amepre.2011.10.026.

40. Fitzgibbons TP, Kogan S, Aouadi M, Hendricks GM, Straubhaar J, Czech MP. Similarity of mouse perivascular and brown adipose tissues and their resistance to diet-induced inflammation. Am J Physiol Heart Circ Physiol 2011; 301: H1425-1437. DOI: 10.1152/ajpheart.00376.2011.

41. Fraser A, Tilling K, Macdonald-Wallis C, Sattar N, Brion $\mathrm{MJ}$, Benfield L, et al. Association of maternal weight gain in pregnancy with offspring obesity and metabolic and vascular traits in childhood. Circulation 2010; 121: 2557-2564. DOI: 10.1161/CIRCULATIONAHA.109.906081.

42. Gao YJ, Lu C, Su LY, Sharma AM, Lee RM. Modulation of vascular function by perivascular adipose tissue: the role of endothelium and hydrogen peroxide. Br J Pharmacol 2007; 151: 323-331. DOI: 10.1038/sj.bjp.0707228.

43. Gastaldelli A, Basta G. Ectopic fat and cardiovascular disease: what is the link? Nutr Metab Cardiovasc Dis 2010; 20: 481-490. DOI: 10.1016/j.numecd.2010.05.005.

44. Gehrke S, Brueckner B, Schepky A, Klein J, Iwen A, Bosch TC, et al. Epigenetic regulation of depot-specific gene expression in adipose tissue. PLoS One 2013; 8: e82516. DOI: 10.1371/journal.pone.0082516.

45. Gil-Ortega M, Somoza B, Huang Y, Gollasch M, FernandezAlfonso MS. Regional differences in perivascular adipose tissue impacting vascular homeostasis. Trends Endocrinol Metab 2015; 26: 367-375. DOI: 10.1016/j.tem.2015.04.003. 
46. Goda M, Takatori S, Atagi S, Hashikawa-Hobara N, Kawasaki H. Nerve growth factor facilitates perivascular innervation in neovasculatures of mice. J Pharmacol Sci 2016; 131: 251-258. DOI: 10.1016/j.jphs.2016.07.002.

47. Goncalves N, Falcao-Pires I, Leite-Moreira AF. Adipokines and their receptors: potential new targets in cardiovascular diseases. Future Med Chem 2015; 7: 139-157. DOI: 10.4155/ fmc.14.147.

48. Goto T, Naknukool S, Yoshitake R, Hanafusa Y, Tokiwa S, Li Y, et al. Proinflammatory cytokine interleukin-1beta suppresses cold-induced thermogenesis in adipocytes. Cytokine 2016; 77: 107-114. DOI: 10.1016/j.cyto.2015.11.001.

49. Grundy SM, Brewer HB, Jr., Cleeman JI, Smith SC, Jr., Lenfant C, American Heart A, et al. Definition of metabolic syndrome: Report of the National Heart, Lung, and Blood Institute/American Heart Association conference on scientific issues related to definition. Circulation 2004; 109: 433438. DOI: 10.1161/01.CIR.0000111245.75752.C6.

50. Hanzu FA, Musri MM, Sanchez-Herrero A, Claret M, Esteban Y, Kaliman P, et al. Histone demethylase KDM1A represses inflammatory gene expression in preadipocytes. Obesity (Silver Spring) 2013; 21: E616-625. DOI: 10.1002/ oby.20479.

51. Heberlein A, Muschler M, Frieling H, Behr M, Eberlein C, Wilhelm J, et al. Epigenetic down regulation of nerve growth factor during alcohol withdrawal. Addict Biol 2013; 18: 508-510. DOI: 10.1111/j.1369-1600.2010.00307.x.

52. Hou N, Liu Y, Han F, Wang D, Hou X, Hou S, et al. Irisin improves perivascular adipose tissue dysfunction via regulation of the heme oxygenase-1/adiponectin axis in dietinduced obese mice. J Mol Cell Cardiol 2016; 99: 188-196. DOI: 10.1016/j.yjmcc.2016.09.005.

53. Houben AJ, Eringa EC, Jonk AM, Serne EH, Smulders YM, Stehouwer CD. Perivascular fat and the microcirculation: Relevance to insulin resistance, diabetes, and cardiovascular disease. Curr Cardiovasc Risk Rep 2012; 6: 80-90. DOI: 10.1007/s12170-011-0214-0.

54. Houde AA, Legare C, Biron S, Lescelleur O, Biertho L, Marceau S, et al. Leptin and adiponectin DNA methylation levels in adipose tissues and blood cells are associated with BMI, waist girth and LDL-cholesterol levels in severely obese men and women. BMC Med Genet 2015; 16: 29. DOI: 10.1186/s12881-015-0174-1.

55. Iacobellis G. Epicardial fat: a new cardiovascular therapeutic target. Curr Opin Pharmacol 2016; 27: 13-18. DOI: 10.1016/j.coph.2016.01.004

56. Inagaki T, Sakai J, Kajimura S. Transcriptional and epigenetic control of brown and beige adipose cell fate and function. Nat Rev Mol Cell Biol 2016; 17: 480-495. DOI: 10.1038/nrm.2016.62

57. Khalyfa A, Carreras A, Hakim F, Cunningham JM, Wang Y, Gozal D. Effects of late gestational high-fat diet on body weight, metabolic regulation and adipokine expression in offspring. Int J Obes (Lond) 2013; 37: 1481-1489. DOI: 10.1038/ijo.2013.12

58. Kim AY, Park YJ, Pan X, Shin KC, Kwak SH, Bassas AF, et al. Obesity-induced DNA hypermethylation of the adiponectin gene mediates insulin resistance. Nat Commun 2015; 6: 7585. DOI: 10.1038/ncomms8585

59. Kohli RM, Zhang Y. TET enzymes, TDG and the dynamics of DNA demethylation. Nature 2013; 502: 472-479. DOI: 10.1038 /nature 12750

60. Kostopoulos CG, Spiroglou SG, Varakis JN, Apostolakis E, Papadaki HH. Chemerin and CMKLR1 expression in human arteries and periadventitial fat: a possible role for local chemerin in atherosclerosis? BMC Cardiovasc Disord 2014; 14:56-65. DOI: http://www.biomedcentral.com/1471$2261 / 14 / 56$

61. Laker RC, Lillard TS, Okutsu M, Zhang M, Hoehn KL, Connelly JJ, et al. Exercise prevents maternal high-fat dietinduced hypermethylation of the Pgc-1alpha gene and agedependent metabolic dysfunction in the offspring. Diabetes 2014; 63: 1605-1611. DOI: 10.2337/db13-1614.

62. Laker RCW, M.E.; Connelly, J.J. and Yan, Z. Epigenetic origins of metabolic disease: The impact of the maternal condition to the offspring epigenome and later health consequences. Food Science and Human Wellness 2013; 2: 1-11.

63. Lastra G, Manrique C. Perivascular adipose tissue, inflammation and insulin resistance: link to vascular dysfunction and cardiovascular disease. Horm Mol Biol Clin Investig 2015; 22: 19-26. DOI: 10.1515/hmbci-2015-0010.

64. Lee HY, Despres JP, Koh KK. Perivascular adipose tissue in the pathogenesis of cardiovascular disease. Atherosclerosis 2013; 230: 177-184. DOI: 10.1016/j.atherosclerosis.2013.07.037.

65. Li C, Wang Z, Wang C, Ma Q, Zhao Y. Perivascular adipose tissue-derived adiponectin inhibits collar-induced carotid atherosclerosis by promoting macrophage autophagy. PLoS One 2015; 10: e0124031. DOI: 10.1371/journal. pone.0124031.

66. Liang X, Yang Q, Zhang L, Maricelli JW, Rodgers BD, Zhu MJ, et al. Maternal high-fat diet during lactation impairs thermogenic function of brown adipose tissue in offspring mice. Sci Rep 2016; 6: 34345. DOI: 10.1038/ srep34345. 
67. Lindholm CR, Ertel RL, Bauwens JD, Schmuck EG, Mulligan JD, Saupe KW. A high-fat diet decreases AMPK activity in multiple tissues in the absence of hyperglycemia or systemic inflammation in rats. J Physiol Biochem 2013; 69: 165-175. DOI: 10.1007/s13105-012-0199-2.

68. Long JZ, Svensson KJ, Tsai L, Zeng X, Roh HC, Kong X, et al. A smooth muscle-like origin for beige adipocytes. Cell Metab 2014; 19: 810-820. DOI: 10.1016/j.cmet.2014.03.025.

69. Lynch FM, Withers SB, Yao Z, Werner ME, Edwards G, Weston $\mathrm{AH}$, et al. Perivascular adipose tissue-derived adiponectin activates $\mathrm{BK}(\mathrm{Ca})$ channels to induce anticontractile responses. Am J Physiol Heart Circ Physiol 2013; 304: H786-795. DOI: 10.1152/ajpheart.00697.2012.

70. Mahabadi AA, Reinsch N, Lehmann N, Altenbernd J, Kalsch H, Seibel RM, et al. Association of pericoronary fat volume with atherosclerotic plaque burden in the underlying coronary artery: a segment analysis. Atherosclerosis 2010; 211: 195-199. DOI: 10.1016/j.atherosclerosis.2010.02.013.

71. Mamun AA, O'Callaghan M, Callaway L, Williams G, Najman J, Lawlor DA. Associations of gestational weight gain with offspring body mass index and blood pressure at 21 years of age: evidence from a birth cohort study. Circulation 2009; 119: 1720-1727. DOI: 10.1161/CIRCULATIONAHA.108.813436.

72. Masuyama H, Hiramatsu Y. Effects of a high-fat diet exposure in utero on the metabolic syndrome-like phenomenon in mouse offspring through epigenetic changes in adipocytokine gene expression. Endocrinology 2012; 153: 28232830. DOI: 10.1210/en.2011-2161.

73. Masuyama H, Mitsui T, Nobumoto E, Hiramatsu Y. The Effects of High-Fat Diet Exposure In Utero on the Obesogenic and Diabetogenic Traits Through Epigenetic Changes in Adiponectin and Leptin Gene Expression for Multiple Generations in Female Mice. Endocrinology 2015; 156: 2482-2491. DOI: 10.1210/en.2014-2020.

74. Maurovich-Horvat P, Kallianos K, Engel LC, Szymonifka J, Fox CS, Hoffmann U, et al. Influence of pericoronary adipose tissue on local coronary atherosclerosis as assessed by a novel MDCT volumetric method. Atherosclerosis 2011; 219: 151-157. DOI: 10.1016/j.atherosclerosis.2011.06.049.

75. Nacci C, Leo V, De Benedictis L, Potenza MA, Sgarra L, De Salvia MA, et al. Infliximab therapy restores adiponectin expression in perivascular adipose tissue and improves endothelial nitric oxide-mediated vasodilation in mice with type 1 diabetes. Vascul Pharmacol 2016. DOI: 10.1016/j. vph.2016.08.007.

76. Nava E, Llorens S. The paracrine control of vascular motion. A historical perspective. Pharmacol Res 2016; 113:
125-145. DOI: 10.1016/j.phrs.2016.08.003.

77. Nechad M, Ruka E, Thibault J. Production of nerve growth factor by brown fat in culture: relation with the in vivo developmental stage of the tissue. Comp Biochem Physiol Comp Physiol 1994; 107: 381-388.

78. Nisoli E, Tonello C, Benarese M, Liberini P, Carruba MO. Expression of nerve growth factor in brown adipose tissue: implications for thermogenesis and obesity. Endocrinology 1996; 137: 495-503. DOI: 10.1210/endo.137.2.8593794.

79. Norheim F, Langleite TM, Hjorth M, Holen T, Kielland A, Stadheim HK, et al. The effects of acute and chronic exercise on PGC-1alpha, irisin and browning of subcutaneous adipose tissue in humans. FEBS J 2014; 281: 739-749. DOI: 10.1111/febs.12619.

80. Ohman MK, Luo W, Wang H, Guo C, Abdallah W, Russo HM, et al. Perivascular visceral adipose tissue induces atherosclerosis in apolipoprotein E deficient mice. Atherosclerosis 2011; 219: 33-39. DOI: 10.1016/j.atherosclerosis.2011.07.012.

81. Ohno H, Shinoda K, Ohyama K, Sharp LZ, Kajimura S. EHMT1 controls brown adipose cell fate and thermogenesis through the PRDM16 complex. Nature 2013; 504: 163 167. DOI: $10.1038 /$ nature 12652.

82. Oken E. Maternal and child obesity: the causal link. Obstet Gynecol Clin North Am 2009; 36: 361-377, ix-x. DOI: 10.1016/j.ogc.2009.03.007.

83. Oral EA, Simha V, Ruiz E, Andewelt A, Premkumar A, Snell $\mathrm{P}$, et al. Leptin-replacement therapy for lipodystrophy. N Engl J Med 2002; 346: 570-578. DOI: 10.1056/NEJMoa012437.

84. Owen MK, Witzmann FA, McKenney ML, Lai X, Berwick ZC, Moberly SP, et al. Perivascular adipose tissue potentiates contraction of coronary vascular smooth muscle: influence of obesity. Circulation 2013; 128: 9-18. DOI: 10.1161/ CIRCULATIONAHA.112.001238.

85. Ozen G, Daci A, Norel X, Topal G. Human perivascular adipose tissue dysfunction as a cause of vascular disease: Focus on vascular tone and wall remodeling. Eur J Pharmacol 2015; 766: 16-24. DOI: 10.1016/j.ejphar.2015.09.012.

86. Öztürk G, Kaya O, Gürel EE, Palabiyik O, Kunduracilar $\mathrm{H}$, Süt $\mathrm{N}$, et al. Acute supramaximal exercise-induced adiponectin increase in healthy volunteers: Involvement of natriuretic peptides. Adipobiology 2016; 8: 19-27.

87. Peeraully MR, Jenkins JR, Trayhurn P. NGF gene expression and secretion in white adipose tissue: regulation in 3T3-L1 adipocytes by hormones and inflammatory cytokines. Am J Physiol Endocrinol Metab 2004; 287: E331339. DOI: 10.1152/ajpendo.00076.2004. 
88. Pfluger PT, Herranz D, Velasco-Miguel S, Serrano M, Tschop MH. Sirt1 protects against high-fat diet-induced metabolic damage. Proc Natl Acad Sci U S A 2008; 105: 9793-9798. DOI: 10.1073/pnas.0802917105.

89. Pojoga LH, Williams JS, Yao TM, Kumar A, Raffetto JD, do Nascimento GR, et al. Histone demethylase LSD1 deficiency during high-salt diet is associated with enhanced vascular contraction, altered NO-cGMP relaxation pathway, and hypertension. Am J Physiol Heart Circ Physiol 2011; 301: H1862-1871. DOI: 10.1152/ajpheart.00513.2011.

90. Rocha-Rodrigues S, Rodriguez A, Becerril S, Ramirez B, Goncalves IO, Beleza J, et al. Physical exercise remodels visceral adipose tissue and mitochondrial lipid metabolism in rats fed a high-fat diet. Clin Exp Pharmacol Physiol 2016. DOI: 10.1111/1440-1681.12706.

91. Rocha-Rodrigues S, Rodriguez A, Gouveia AM, Goncalves IO, Becerril S, Ramirez B, et al. Effects of physical exercise on myokines expression and brown adipose-like phenotype modulation in rats fed a high-fat diet. Life Sci 2016; 165: 100-108. DOI: 10.1016/j.lfs.2016.09.023.

92. Ronn T, Volkov P, Davegardh C, Dayeh T, Hall E, Olsson $\mathrm{AH}$, et al. A six months exercise intervention influences the genome-wide DNA methylation pattern in human adipose tissue. PLoS Genet 2013; 9: e1003572. DOI: 10.1371/journal.pgen.1003572.

93. Rosen ED, Spiegelman BM. What we talk about when we talk about fat. Cell 2014; 156: 20-44. DOI: 10.1016/j. cell.2013.12.012.

94. Ryan VH, German AJ, Wood IS, Hunter L, Morris P, Trayhurn P. NGF gene expression and secretion by canine adipocytes in primary culture: upregulation by the inflammatory mediators LPS and TNFalpha. Horm Metab Res 2008; 40: 861-868. DOI: 10.1055/s-0028-1083782.

95. Sacks H, Symonds ME. Anatomical locations of human brown adipose tissue: functional relevance and implications in obesity and type 2 diabetes. Diabetes 2013; 62: 1783-1790. DOI: 10.2337/db12-1430.

96. Sacks HS, Fain JN, Bahouth SW, Ojha S, Frontini A, Budge $\mathrm{H}$, et al. Adult epicardial fat exhibits beige features. J Clin Endocrinol Metab 2013; 98: E1448-1455. DOI: 10.1210/ jc. 2013-1265.

97. Samuelsson AM, Matthews PA, Argenton M, Christie MR, McConnell JM, Jansen EH, et al. Diet-induced obesity in female mice leads to offspring hyperphagia, adiposity, hypertension, and insulin resistance: a novel murine model of developmental programming. Hypertension 2008; 51: 383392. DOI: 10.1161/HYPERTENSIONAHA.107.101477.

98. Sanchez-Infantes D, Cereijo R, Peyrou M, Piquer-Garcia
I, Stephens JM, Villarroya F. Oncostatin m impairs brown adipose tissue thermogenic function and the browning of subcutaneous white adipose tissue. Obesity (Silver Spring) 2016. DOI: 10.1002/oby.21679.

99. Satoor SN, Puranik AS, Kumar S, Williams MD, Ghale M, Rahalkar A, et al. Location, location, location: Beneficial effects of autologous fat transplantation. Sci Rep 2011; 1: 81. DOI: $10.1038 /$ srep00081.

100. Shankar K, Harrell A, Liu X, Gilchrist JM, Ronis MJ, Badger TM. Maternal obesity at conception programs obesity in the offspring. Am J Physiol Regul Integr Comp Physiol 2008; 294: R528-538. DOI: 10.1152/ajpregu.00316.2007

101. Sharma G, Tao M, Ding K, Yu D, King W, Deyneko G, et al. Perivascular adipose adiponectin correlates with symptome status of patients undergoing carotid endarterectomy. Stroke 2015; 46: 1696-1699. DOI: 10.1161/ STROKEAHA.114.008468

102. Shimizu I, Walsh K. The whitening of brown fat and its implications for weight management in obesity. Curr Obes Rep 2015; 4: 224-229. DOI: 10.1007/s13679-015-0157-8

103. Shimomura I, Funahashi T, Matsuzawa Y. Metabolic syndrome, adiponectin and fat ROS. Biomed Rev 2006; 17: 1-10.

104. Shore A, Karamitri A, Kemp P, Speakman JR, Lomax MA. Role of Ucp1 enhancer methylation and chromatin remodelling in the control of Ucp1 expression in murine adipose tissue. Diabetologia 2010; 53: 1164-1173. DOI: 10.1007/ s00125-010-1701-4

105. Siersbaek R, Nielsen R, Mandrup S. Transcriptional networks and chromatin remodeling controlling adipogenesis. Trends Endocrinol Metab 2012; 23: 56-64. DOI: 10.1016/j. tem.2011.10.001.

106. Sornelli F, Fiore M, Chaldakov GN, Aloe L. Adipose tissue-derived nerve growth factor and brain-derived neurotrophic factor: results from experimental stress and diabetes. Gen Physiol Biophys 2009; 28 Spec No: 179-183.

107. Sun Y, Li J, Xiao N, Wang M, Kou J, Qi L, et al. Pharmacological activation of AMPK ameliorates perivascular adipose/endothelial dysfunction in a manner interdependent on AMPK and SIRT1. Pharmacol Res 2014; 89: 19-28. DOI: 10.1016/j.phrs.2014.07.006.

108. Szasz T, Bomfim GF, Webb RC. The influence of perivascular adipose tissue on vascular homeostasis. Vasc Health Risk Manag 2013; 9: 105-116. DOI: 10.2147/VHRM.S33760.

109. Takaoka M, Suzuki H, Shioda S, Sekikawa K, Saito Y, Nagai $\mathrm{R}$, et al. Endovascular injury induces rapid phenotypic changes in perivascular adipose tissue. Arterioscler Thromb Vasc Biol 2010; 30: 1576-1582. DOI: 10.1161/ATVBAHA.110.207175. 
110. Tang Y, Tian XC. JAK-STAT3 and somatic cell reprogramming. JAKSTAT 2013; 2: e24935. DOI: 10.4161/jkst.24935.

111. Tao W, Zhou W, Wang Y, Sun T, Wang H, Zhang Z, et al. Histone deacetylase inhibitor-induced emergence of synaptic delta-opioid receptors and behavioral antinociception in persistent neuropathic pain. Neuroscience 2016; 339: 5463. DOI: 10.1016/j.neuroscience.2016.09.015.

112. Van de Voorde J, Pauwels B, Boydens C, Decaluwe K. Adipocytokines in relation to cardiovascular disease. Metabolism 2013; 62: 1513-1521. DOI: 10.1016/j.metabol.2013.06.004.

113. Verhagen SN, Visseren FL. Perivascular adipose tissue as a cause of atherosclerosis. Atherosclerosis 2011; 214: 3-10. DOI: 10.1016/j.atherosclerosis.2010.05.034.

114. Villarroya FC, R ; Villarroya, J and Giralt, M. Brown adipose tissue as a secretory organ. NATURE REVIEWS ENDOCRINOLOGY 2016; 12.

115. Wakana N, Irie D, Kikai M, Terada K, Yamamoto K, Kawahito $\mathrm{H}$, et al. Maternal high-fat diet exaggerates atherosclerosis in adult offspring by augmenting periaortic adipose tissue-specific proinflammatory response. Arterioscler Thromb Vasc Biol 2015; 35: 558-569. DOI: 10.1161/ATVBAHA.114.305122.

116. Wang B, Jenkins JR, Trayhurn P. Expression and secretion of inflammation-related adipokines by human adipocytes differentiated in culture: integrated response to TNF-alpha. Am J Physiol Endocrinol Metab 2005; 288: E731-740. DOI: 10.1152/ajpendo.00475.2004.

117. Wang J, Chen D, Cheng XM, Zhang QG, Peng YP, Wang LJ, et al. Influence of phenotype conversion of epicardial adipocytes on the coronary atherosclerosis and its potential molecular mechanism. Am J Transl Res 2015; 7: 1712-1723.

118. Wang W, Seale P. Control of brown and beige fat development. Nat Rev Mol Cell Biol 2016; 17: 691-702. DOI: 10.1038/nrm.2016.96.

119. Wojcicka G, Jamroz-Wisniewska A, Atanasova P, Chaldakov GN, Chylinska-Kula B, Beltowski J. Differential effects of statins on endogenous $\mathrm{H} 2 \mathrm{~S}$ formation in perivascular adipose tissue. Pharmacol Res 2011; 63: 68-76. DOI: 10.1016/j. phrs.2010.10.011.

120. Yamauchi T, Kamon J, Waki H, Terauchi Y, Kubota N, Hara $\mathrm{K}$, et al. The fat-derived hormone adiponectin reverses insulin resistance associated with both lipoatrophy and obesity. Nat Med 2001; 7: 941-946. DOI: 10.1038/90984.

121. Yanev S, Aloe L, Fiore F, Chaldakov GN. Neurotrophic and metabotrophic potential of nerve growth factor and brainderived neurotrophic factor: Linking cardiometabolic and neuropsychiatric diseases. World J Pharmacol 2013; 2: 9299. DOI:10.5497/wjp.v2.i4.92

122. Yang Q, Liang X, Sun X, Zhang L, Fu X, Rogers CJ, et al. AMPK/alpha-ketoglutarate axis dynamically mediates DNA demethylation in the Prdm16 promoter and brown adipogenesis. Cell Metab 2016; 24: 542-554. DOI: 10.1016/j. cmet.2016.08.010.

123. Yang Z, Chen H, Huo L, Yang Z, Bai Y, Fan X, et al. Epigenetic inactivation and tumor-suppressor behavior of NGFR in human colorectal cancer. Mol Cancer Res 2015; 13: 107119. DOI: 10.1158/1541-7786.MCR-13-0247

124. Zaborska KE, Wareing M, Edwards G, Austin C. Loss of anti-contractile effect of perivascular adipose tissue in offspring of obese rats. Int J Obes (Lond) 2016; 40: 1205-1214. DOI: 10.1038/ijo.2016.62 